\title{
The Effect of Training at 2100-m Altitude on Running Speed and Session Rating of Perceived Exertion at Different Intensities in Elite Middle-Distance Runners
}

\author{
Avish P. Sharma, Philo U. Saunders, Laura A. Garvican-Lewis, Brad Clark, Jamie Stanley, \\ Eileen Y. Robertson, and Kevin G. Thompson
}

\begin{abstract}
Purpose: To determine the effect of training at 2100-m natural altitude on running speed (RS) during training sessions over a range of intensities relevant to middle-distance running performance. Methods: In an observational study, 19 elite middle-distance runners (mean $\pm \mathrm{SD}$ age $\left.25 \pm 5 \mathrm{y}, \mathrm{VO}_{2} \mathrm{max}, 71 \pm 5 \mathrm{~mL} \cdot \mathrm{kg}^{-1} \cdot \mathrm{min}^{-1}\right)$ completed either 4-6 wk of sea-level training $(\mathrm{CON}, \mathrm{n}=$ 7) or a 4- to 5-wk natural altitude-training camp living at $2100 \mathrm{~m}$ and training at $1400-2700 \mathrm{~m}($ ALT, $\mathrm{n}=12)$ after a period of sea-level training. Each training session was recorded on a GPS watch, and athletes also provided a score for session rating of perceived exertion (sRPE). Training sessions were grouped according to duration and intensity. RS (km/h) and sRPE from matched training sessions completed at sea level and $2100 \mathrm{~m}$ were compared within ALT, with sessions completed at sea level in CON describing normal variation. Results: In ALT, RS was reduced at altitude compared with sea level, with the greatest decrements observed during threshold- and $\mathrm{VO}_{2}$ max-intensity sessions (5.8\% and 3.6\%, respectively). Velocity of low-intensity and race-pace sessions completed at a lower altitude $(1400 \mathrm{~m})$ and/or with additional recovery was maintained in ALT, though at a significantly greater sRPE $(P=.04$ and .05 , respectively). There was no change in velocity or sRPE at any intensity in CON. Conclusion: RS in elite middle-distance athletes is adversely affected at 2100-m natural altitude, with levels of impairment dependent on the intensity of training. Maintenance of RS at certain intensities while training at altitude can result in a higher perceived exertion.
\end{abstract}

Keywords: exercise prescription, load monitoring, endurance.

Live high, train high (LHTH), or classic altitude training, is used by endurance athletes to facilitate adaptation and improve performance. ${ }^{1-5}$ Training sessions completed in hypoxia evoke a higher physiological load than equivalent sessions completed in normoxia. ${ }^{6}$ However, the reduced partial pressure of oxygen and subsequent re-duction in oxygen transport and uptake at race-like intensities $^{7-9}$ affects both performance and perceived exertion. In Australian Rules footballers undertaking altitude training at 2100 $\mathrm{m}$, rating of perceived exertion (RPE) scores were 13\% higher than controls completing similar, predominantly aerobic training at sea level. ${ }^{10}$ Perceptual training data from endurance athletes at natural altitude is scarce, and perhaps would differ from footballers given that a larger volume of endurance training and higher frequency of altitude training is completed.

Impaired performances in 3000-m time trials have been reported ${ }^{11}$ for elite runners at natural altitude compared with sea level, but the trials were performed within 48 hours of arrival at altitude, contravening the usual practice of allowing an acclimatization period before progressing to intense training. ${ }^{12}$ Nevertheless, slower running velocities at altitude have also been reported following acclimatization, ${ }^{8}$ however with an improvement in performance over

Sharma, Saunders, Garvican-Lewis, Clark, and Thompson are with the Research Inst for Sport and Exercise (UCRISE), University of Canberra, Bruce, ACT, Australia. Sharma, Saunders, and Garvican-Lewis are also with Physiology, Australian Inst of Sport, Bruce, ACT, Australia. Stanley and Robertson are with the Physiology Dept, South Australian Sports Institute, Adelaide, SA, Australia. Address author correspondence to Avish P. Sharma at avish.sharma@ausport.gov.au. the course of altitude exposure. ${ }^{13,14}$ Beyond these investigations, few data exist in scientific literature regarding the effect of moderate altitude on running speed (RS) in elite athletes.

It is important to consider the effects altitude may have on performance over the range of intensities at which distance runners train, ${ }^{15}$ because some elite athletes may be unable to maintain the training velocities required for competitive fitness. ${ }^{16}$ An investigation in elite cyclists competing in a stage race at altitude demonstrated mean maximal power output for intervals up to 60 seconds duration were minimally affected at 1000 to $2000 \mathrm{~m}$ altitude, compared with when completed in a race simulation near sea level; however, above $2000 \mathrm{~m}$, performance was impaired by up to $10 \% .{ }^{17}$ Thus, it remains unclear which training intensities may be adversely affected at altitude, and there is a lack of published data from elite athletes undertaking natural altitude training in a real-world setting on which to base recommendations regarding optimal practice.

Therefore, through observing a group of elite middle-distance athletes participating in a LHTH altitude camp, this investigation sought to determine the effect of training at 2100-m natural altitude on RS during training sessions covering a range of intensities relevant to middle-distance running performance.

\section{Methods}

\section{Subjects}

Nineteen elite middle-distance (800-5000 m) runners (13 male, 6 female; mean $\pm \mathrm{SD}$ age, $\left.25 \pm 5 \mathrm{y}, \mathrm{VO}_{2} \max 71 \pm 5 \mathrm{~mL} \cdot \mathrm{kg}^{-1} \cdot \mathrm{min}^{-1}\right)$ participated in the investigation. Over two-thirds were ranked in 
the top 15 for their event in Australia at the time of writing. Seven athletes ( 5 male, 2 female; age $23 \pm 5 \mathrm{y}, \mathrm{VO}_{2} \max , 72 \pm 6 \mathrm{~mL} \cdot \mathrm{kg}^{-1}$. min $^{-1}$ ) completed 4 to 6 weeks of training at or near sea level (CON). Training occurred after the domestic track season, when the athletes were in an endurance phase of training in preparation for the winter cross-country season. Their training included low-, threshold-, and $\mathrm{VO}_{2}$ max-intensity training. Twelve athletes ( 8 male, 4 female; age $\left.26 \pm 5 \mathrm{y}, \mathrm{VO}_{2} \max 70 \pm 5 \mathrm{~mL} \cdot \mathrm{kg}^{-1} \cdot \mathrm{min}^{-1}\right)$ participated in a 4- to 5-week natural-altitude training camp (ALT) in Flagstaff, AZ, USA (2100-m elevation) after 4 weeks of sea-level training, also following the domestic track season. Five athletes had previously trained in Flagstaff and the remainder had experienced altitude training at 1600 to $1800 \mathrm{~m}$ in Australia. These athletes were preparing for competition before and after LHTH, therefore their training also included middle-distance-specific race-pace sessions. Training was predominantly completed between 2100 to $2700 \mathrm{~m}$ with the exception of a weekly race-pace session, usually completed at 1400 $\mathrm{m}$, though occasionally at $2100 \mathrm{~m}$. All procedures and risks were explained to participants before they provided written consent to participate. Ethical approval for the investigation was granted by the institutional ethics committees and all procedures complied with the Declaration of Helsinki.

\section{Design}

The study was an observational design examining the training of elite middle-distance runners to compare responses between sealevel and altitude sessions in those athletes completing LHTH. Participants' training sessions were designed by their coaches and were not manipulated or directly influenced as part of the study.

\section{Procedures}

Over the observational period, each athlete recorded his or her training on a GPS watch (Forerunner, Garmin International, Kansas, USA) to measure distance completed and RS during each training session. In addition, for each training session, athletes provided a session rating of perceived exertion (sRPE) score on a modified Borg scale. ${ }^{18}$ Training sessions were categorized according to intensity and duration, as described in Table 1. In ALT, all training sessions completed within the 3 weeks before altitude training, and repeated at altitude following a week of acclimatization, were considered for analysis to determine the effect of training at altitude on RS and SRPE. Where repeats of the same session occurred within the sea-level or altitude periods a mean value of those sessions was calculated and used for comparison. In CON, identical training sessions repeated within 2 weeks were included for analysis to illustrate normal variation in training. Matched training sessions were completed on similar terrain, topography and weather conditions. All race-pace training was completed on standardized outdoor 400-m athletic tracks.

\section{Statistical Analyses}

Average speed $(\mathrm{km} / \mathrm{h})$ and sRPE from matched training sessions were analyzed within groups (sea level vs altitude in ALT, sea level vs. sea level in CON). In addition, an integrated approach was used to present these data with SRPE divided by RS to determine the ratio of exertion to running velocity (ie, RPE units per $\mathrm{km} / \mathrm{h} \mathrm{RS}$ ) at each training intensity within groups. Data were compared using paired $t$ tests, with effect sizes (Cohen $d$ ) and percentage changes also calculated along with $90 \%$ confidence limits (CL). All other variables are displayed as mean \pm SD unless otherwise stated, and alpha was set at $P \leq .05$.

\section{Results}

\section{Change in RS at Altitude}

The changes in RS across the spectrum of training intensities in this investigation are shown in Table 2. No differences were observed for $\mathrm{RS}$ in CON. In ALT, RS was reduced at altitude overall (19.1 \pm 3.9

Table 1 Characterization and Examples of Training Sessions at Different Intensities

\begin{tabular}{|c|c|c|c|c|}
\hline & Low intensity & Threshold & $\mathrm{VO}_{2} \max$ & Race pace \\
\hline Description & $\begin{array}{l}\text { Continuous low- } \\
\text { intensity running, } \\
\text { completed at } 2100- \\
2700 \mathrm{~m}\end{array}$ & $\begin{array}{l}\text { Continuous running and fartlek } \\
\text { sessions ranging } 10-30 \mathrm{~min} \\
\text { duration performed around lac- } \\
\text { tate threshold, at } 2100 \mathrm{~m}\end{array}$ & $\begin{array}{l}\text { Longer intervals ranging } 1-6 \\
\text { min length completed around } \\
\text { the velocity at } \mathrm{VO}_{2} \max \text {, at } \\
2100 \mathrm{~m}\end{array}$ & $\begin{array}{l}\text { Intervals } 2 \text { min or shorter performed at } \\
\text { each athlete's middle-distance race pace } \\
\text { or faster-these were completed either } \\
\text { in Flagstaff at } 2100 \mathrm{~m} \text { or in Sedona at } \\
1400 \mathrm{~m}\end{array}$ \\
\hline \multirow[t]{10}{*}{ Sessions } & \multirow{10}{*}{$\begin{array}{l}\text { Continuous running } \\
>70 \text { min }\end{array}$} & \multirow{5}{*}{$\begin{array}{l}\text { 3-km threshold } \\
30 \text {-min threshold } \\
4 \times 5 \text { min on } 2 \text {-min jog } \\
1,2,3,4,3,2,1 \text { min on } 1 \text {-min } \\
\text { float }-22 \text { min }\end{array}$} & \multirow{2}{*}{$\begin{array}{l}4-6 \times 1 \mathrm{~km} \text { on } 4: 30 / 5: 00 \\
\text { cycle }\end{array}$} & \multirow{2}{*}{$\begin{array}{l}2 \times 3 \times 400 \mathrm{~m} \text { with } 60-\mathrm{s} \text { recovery and } \\
5: 00 \text { between sets }(1400 \mathrm{~m})\end{array}$} \\
\hline & & & & \\
\hline & & & \multirow{6}{*}{$\begin{array}{l}4 \times 1600 \mathrm{~m} \text { with } 2 \text {-min recov- } \\
\text { ery } \\
3 \times 3,2,1 \mathrm{~min} \text { with equal } \\
\text { walk/jog recovery } \\
16 \times 400 \mathrm{~m} \text { on } 2 \text {-min cycle } \\
1600 \mathrm{~m} \text { tempo, } 5 \text {-min recov- } \\
\text { ery, } 800 \mathrm{~m} \text { fast, } 5 \text {-min recov- } \\
\text { ery, } 1600 \mathrm{~m} \text { tempo }(1600 \mathrm{~s})\end{array}$} & \multirow{2}{*}{$\begin{array}{l}1600-\mathrm{m} \text { tempo, } 5 \mathrm{~min} \text { recovery, } 800 \mathrm{~m} \\
\text { fast, } 5 \mathrm{~min} \text { recovery, } 1600 \mathrm{~m} \text { tempo }(800) \\
(1400 \mathrm{~m})\end{array}$} \\
\hline & & & & \\
\hline & & & & \multirow{3}{*}{$\begin{array}{l}3 \times 4 \times 400 \mathrm{~m} \text { with } 30 / 45 / 60 \text {-s recovery } \\
\text { at sea level and } 60 / 75 / 90 \mathrm{~s} \text { at altitude. } 5 \\
\text { min between sets }(1400 \mathrm{~m})\end{array}$} \\
\hline & & 20 min "Mona" fartlek $-4 \times 90$ & & \\
\hline & & & & \\
\hline & & \multirow{3}{*}{$\begin{array}{l}6 \times(20 \mathrm{~s} \text { hard, } 40 \mathrm{~s} \text { float, } 40 \mathrm{~s} \\
\text { hard, } 80 \mathrm{~s} \text { float })-18 \mathrm{~min}\end{array}$} & & $\begin{array}{l}3 \times(6 \times 200 \mathrm{~m} \text { on } 1: 00 \text { recovery, } 800 \mathrm{~m}, \\
3: 00 \text { recovery })(200 \mathrm{~s})(2100 \mathrm{~m})\end{array}$ \\
\hline & & & $\begin{array}{l}3 \times 1000 \mathrm{~m}, 100 \mathrm{jog}, 500 \mathrm{~m} \\
(1000 \mathrm{~s})\end{array}$ & \multirow[t]{2}{*}{$\begin{array}{l}\text { Taper session }-8 \times 200 \mathrm{~m} \text { with } 1: 30 \\
\text { recovery }(2100 \mathrm{~m})\end{array}$} \\
\hline & & & $\begin{array}{l}3 \times(6 \times 200 \mathrm{~m} \text { on } 1-\mathrm{min} \\
\text { recovery, } 800 \mathrm{~m}, 3: 00 \mathrm{recov}- \\
\text { ery }(800 \mathrm{~s})\end{array}$ & \\
\hline
\end{tabular}




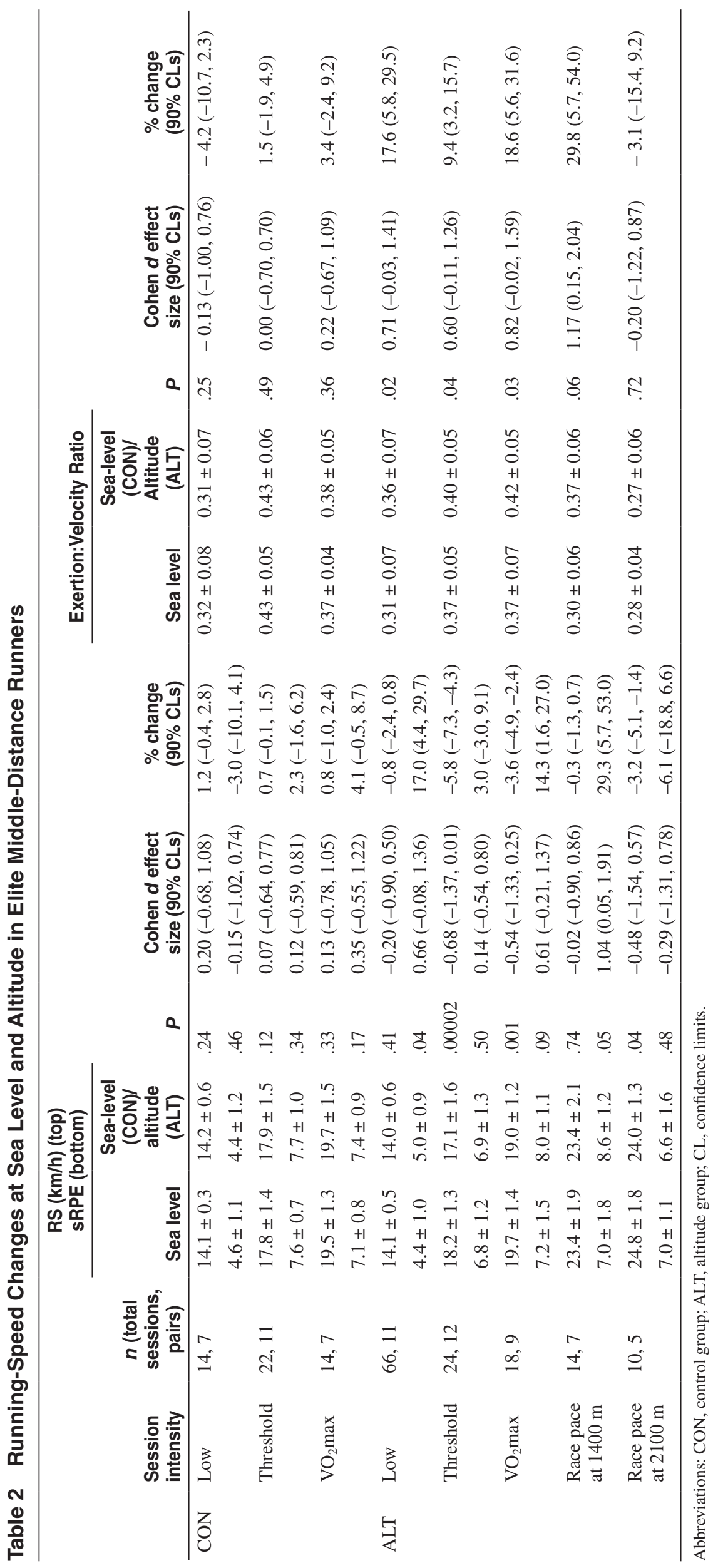


to $18.5 \pm 3.9 \mathrm{~km} / \mathrm{h}, P=.0000003, d=-0.15[-0.50,0.20]$, \% change $(\mathrm{CL})=2.9[-3.8,-2.1])$, with the largest reductions occurring in threshold and $\mathrm{VO}_{2}$ max sessions (Table 2). RS during low-intensity training and race pace sessions conducted at $1400 \mathrm{~m}$ was maintained within $1 \%$ of sea-level values (Table 2). Individual variation for changes in RS at different intensities is shown in Figure 1.

\section{Change in SRPE at Altitude}

sRPE data are shown in Table 2. In ALT, sRPE was greater at altitude compared with sea level overall $(6.6 \pm 1.6$ vs $6.2 \pm 1.7, P=.03, d$ $=0.22[-0.17,0.60], \%$ change $=8.7[3.1,14.3])$, with the largest increases occurring at low-intensity, $\mathrm{VO}_{2} \mathrm{max}$, and race-pace sessions at $1400 \mathrm{~m}$ (Table 2). There were no significant differences in sRPE at any intensity in CON.

\section{Change in Exertion:Velocity Ratio at Altitude}

Exertion:velocity-ratio data are shown in Table 2. In ALT, the ratio was greater at altitude compared with sea level overall $(0.37 \pm 0.07$ vs $0.33 \pm 0.07, P=.00003, d=0.57[0.21,0.92], \%$ change $=15.2$ $[9.3,21.1])$. Trivial to small differences were observed in CON.

\section{Discussion}

The main finding of this investigation is RS in elite middle-distance runners across a range of training intensities is adversely affected at altitude by up to $6 \%$. The level of performance decrement differed depending on the intensity of the training session. A novel finding of the current study was an approximately $9 \%$ increase in SRPE at altitude, which, similar to RS, was specific to different intensities. Furthermore, training at altitude increased the exertion:velocity ratio by approximately $15 \%$. There were no changes in RS, sRPE or exertion:velocity at any intensity in the control group.
In the current study, substantial individual variation in RS at altitude occurred at various training intensities (Figure 1), in accordance with previous findings. ${ }^{11,16}$ Chapman et al ${ }^{16}$ reported those athletes who maintained training speeds during $1000-\mathrm{m}$ intervals close to that at sea level were able to improve performance following altitude, however those who suffered large decrements in performance at altitude were slower in postaltitude time trial performance. Consequently, it has been suggested the maintenance of interval training speed, and therefore oxygen flux through the system is an important aspect for stimulating adaptation and improving performance. ${ }^{6,16}$ In the current investigation, $\mathrm{VO}_{2} \mathrm{max}$ intervals and race-pace intervals at $1400 \mathrm{~m}$ were slower than sea level by $3.6 \%$ and $0.3 \%$ respectively, potentially small enough to maintain associated adaptations. However, high-intensity intervals completed at $2100 \mathrm{~m}$ were more adversely affected than those at $1400 \mathrm{~m}$ (Table 2), which is in agreement with previous findings in cyclists. ${ }^{17}$ To avoid a reduction in race specific fitness, athletes completed shorter race-pace efforts where velocity is not compromised, in some cases with longer recoveries between efforts than at sea level (Table 1), and at a lower altitude to help maintain speed. ${ }^{6}$ While shorter intervals were completed at $2100 \mathrm{~m}$ than at $1400 \mathrm{~m}$ (Table 1), recoveries were maintained, perhaps accounting for the greater decrement in performance.

In the current investigation, athletes training at altitude were able to maintain sea-level speeds for low-intensity sessions and some race-pace sessions (Table 2). With respect to low-intensity aerobic training, submaximal $\mathrm{VO}_{2}$ has been shown to remain unchanged at increasing altitudes, ${ }^{19}$ suggesting if submaximal training intensity can be maintained, oxygen flux through the system will also remain unchanged. However, as a result of maintaining training intensity, sRPE values at altitude were substantially higher. The largest decrement in RS at altitude occurred during threshold intensity training (Table 2). This reduction in longer duration (10-30 $\mathrm{min}$ ) RS at threshold is likely the result

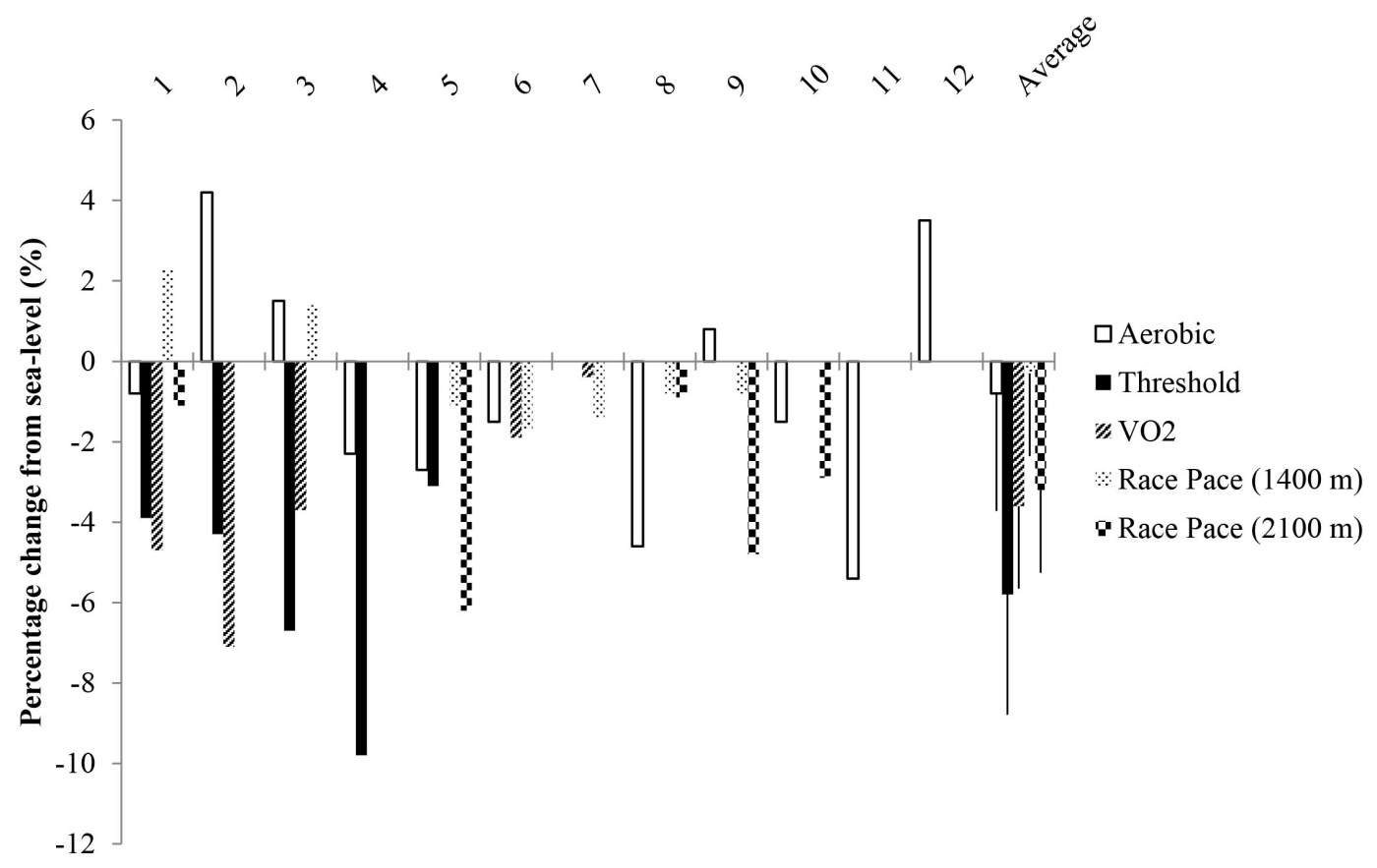

Figure 1 - Individual changes in running speed at different training intensities. Upward bars indicate running speed at altitude was faster than at sea level, and vice versa for downward bars. Each number on the $y$-axis represents a unique individual; not all individuals completed suitable sessions across all training intensities within the observational period. 
of impairment of the aerobic energy system at higher altitudes. An increase in altitude is associated with arterial oxyhemoglobin desaturation and impaired oxygen delivery during exercise which leads to a decrement in $\mathrm{VO}_{2} \max$ in hypoxia, increasing linearly with altitude, ${ }^{20}$ particularly in highly trained endurance athletes. ${ }^{7}$ Notably, the threshold sessions were performed in an identical manner to sea level, whereas certain other sessions were modified to allow for faster running. However, sRPE values were similar to those obtained when equivalent sessions were completed at sea level, suggesting equivalent work rates can be achieved at altitude, but require higher levels of exertion. While the maintenance of training speed and therefore oxygen flux at altitude is beneficial in terms of facilitating physiological adaptation, ${ }^{6}, 16$ the implications of higher perceptual ratings on training loads and athlete wellness is an important consideration.

Novel to the current investigation is the integration of exertion and velocity data when considering training at altitude (ie, exertion/velocity ratio). The ratio describes the relationship between exertion (in this case on a 10-point RPE scale) and running speed in $\mathrm{km} / \mathrm{h}$. An increase in this ratio would suggest a greater level of exertion is required to maintain a certain running speed, a decrease would entail the exertion is easier. In a majority of training intensities completed at altitude (except race-pace sessions at $2100 \mathrm{~m}$ where athletes performed taper sessions at a lower perceived exertion than sea level), the exertion/velocity ratio increased by approximately $9 \%$ to $30 \%$, suggesting athletes would perceive a much greater level of exertion for similar training sessions at altitude compared with sea level. Large increases in the ratio were seen at $\mathrm{VO}_{2} \max$ and race-pace sessions (Table 2) reflecting training at high intensities (ie, race like intensity) is greatly affected at altitude due to changes in oxygen consumption. $6,7,20$

\section{Practical Applications}

- Running speed during threshold and $\mathrm{VO}_{2}$ max intensity training sessions are adversely affected at $2100-\mathrm{m}$ altitude by 6 and $4 \%$ respectively, equating to 13 and $6 \mathrm{~s} / \mathrm{km}$ at the speeds at which elite middle-distance runners train.

- Elite runners maintain intensity of long runs at altitude, but with a higher perceived exertion

- Intensity of race pace intervals can be maintained by allowing for additional/less intense recovery, or completing sessions at a lower moderate altitude (eg, $1400 \mathrm{~m}$ ) to allow for higher physiological loads and perceived exertion conferred by training in hypoxia.

- Performing a session at altitude at the same running speed as when completed at sea level can be up to $30 \%$ harder.

\section{Conclusion}

Running speed in elite middle-distance athletes is adversely affected at 2100-m altitude, with levels of impairment dependent on the intensity of training. However, perceived exertion is increased compared with sea-level training at equivalent running speeds. Therefore, balancing the need to maintain intensity along with managing athlete training loads and fatigue is critical when planning periods of altitude training, and considering potential modifications to training to facilitate an optimal response.

\section{References}

1. Saunders PU, Telford RD, Pyne D, Gore CJ, Hahn AG. Improved race performance in elite middle-distance runners after cumulative altitude exposure. Int J Sports Physiol Perform. 2009;4(1):134-138. PubMed doi:10.1123/ijspp.4.1.134

2. Daniels J, Oldridge N. The effects of alternate exposure to altitude and sea level on world-class middle-distance runners. Med Sci Sports. 1970;2(3):107-112. PubMed

3. Rodríguez FA, Iglesias X, Feriche B, et al. Altitude training in elite swimmers for sea level performance (altitude project). Med Sci Sports Exerc. 2015;47(9):1965-1978. PubMed doi:10.1249/ MSS.0000000000000626

4. Gore CJ, Clark SA, Saunders PU. Nonhematological mechanisms of improved sea-level performance after hypoxic exposure. Med Sci Sports Exerc. 2007;39(9):1600-1609. PubMed doi:10.1249/ mss.0b013e3180de49d3

5. Gore CJ, Sharpe K, Garvican-Lewis LA, et al. Altitude training and haemoglobin mass from the optimised carbon monoxide rebreathing method determined by a meta-analysis. Br J Sports Med. 2013;47:i31-i39. PubMed doi:10.1136/bjsports-2013-092840

6. Saunders PU, Pyne DB, Gore CJ. Endurance training at altitude. High Alt Med Biol. 2009;10:135-148. PubMed doi:10.1089/ ham.2008.1092

7. Chapman RF, Emery M, Stager J. Degree of arterial desaturation in normoxia influences $\mathrm{VO}_{2}$ max decline in mild hypoxia. Med Sci Sports Exerc. 1999;31:658-663. PubMed doi:10.1097/ 00005768-199905000-00006

8. Levine BD, Stray-Gundersen J. "Living high-training low": effect of moderate-altitude acclimatization with low-altitude training on performance. J Appl Physiol. 1997;83(1):102-112. PubMed

9. Chapman RF. The individual response to training and competition at altitude. Br J Sports Med. 2013;47(Suppl 1):i40-i44. PubMed doi:10.1136/bjsports-2013-092837

10. McLean BD, Buttifant D, Gore CJ, White K, Liess C, Kemp J. Physiological and performance responses to a pre-season altitude training camp in elite team sport athletes. Int J Sports Physiol Perform. 2013;8(4):391-399. PubMed doi:10.1123/ijspp.8.4.391

11. Chapman RF, Stager JM, Tanner DA, Stray-Gundersen J, Levine BD. Impairment of 3000-m run time at altitude is influenced by arterial oxyhemoglobin saturation. Med Sci Sports Exerc. 2011;43(9):16491656. PubMed doi:10.1249/MSS.0b013e318211bf45

12. Wilber RL. Altitude Training and Athletic Performance. Champaign, IL: Human Kinetics; 2004.

13. Buchheit M, Hammond K, Bourdon PC, et al. Relative match intensities at high altitude in highly-trained young soccer players (ISA3600). J Sports Sci Med. 2015;14:98-102. PubMed

14. Chapman RF, Karlsen T, Ge RL, Stray-Gundersen J, Levine BD. Living altitude influences endurance exercise performance change over time at altitude. J Appl Physiol. 2016;120(10):1151-1158. PubMed doi:10.1152/japplphysiol.00909.2015

15. Tønnessen E, Sylta Ø, Haugen TA, Hem E, Svendsen IS, Seiler S. The road to gold: training and peaking characteristics in the year prior to a gold medal endurance performance. PLoS One. 2014;9(7):e101796. PubMed doi:10.1371/journal.pone.0101796

16. Chapman RF, Stray-Gundersen J, Levine BD. Individual variation in response to altitude training. J Appl Physiol. 1998;85(4):1448-1456. PubMed

17. Garvican-Lewis LA, Clark B, Martin DT, et al. Impact of altitude on power output during cycling stage racing. PLoS One. 2015;10(12):e0143028. PubMed doi:10.1371/journal.pone. 0143028 
18. Foster C. Monitoring training in athletes with reference to overtraining syndrome. Med Sci Sports Exerc. 1998;30(7):1164-1168. PubMed doi:10.1097/00005768-199807000-00023

19. Clark SA, Bourdon P, Schmidt W, et al. The effect of acute simulated moderate altitude on power, performance and pacing strategies in well-trained cyclists. Eur J Appl Physiol. 2007;102(1):45-55. PubMed doi:10.1007/s00421-007-0554-0

20. Wehrlin JP, Hallén J. Linear decrease in $\mathrm{VO}_{2}$ max and performance with increasing altitude in endurance athletes. Eur J Appl Physiol. 2006;96(4):404-412. PubMed doi:10.1007/s00421-005-0081-9 